\title{
Editorial
}

\section{Climate change and health: a grand challenge and grand opportunity for public health in Canada}

\author{
Ashlee Cunsolo, PhD (1); Sherilee L. Harper, PhD (2)
}

Globally, climate change is profoundly impacting human health. ${ }^{1,2}$ Directly, climate change impacts human health most often via changes in extreme events (e.g. heat waves, drought, heavy rain), resulting in heat- and cold-related morbidity and mortality, unintentional injury and death, and other adverse health outcomes. Indirectly, the impacts of climate change on health are mediated through climate change impacts on ecosystems and human systems, with health impacts from vectorborne, foodborne, and waterborne diseases, respiratory illnesses, occupational health and safety challenges, undernutrition, and negative impacts on mental health and wellness. ${ }^{1,2}$

The impacts of climate change on human health are not evenly distributed or experienced. A variety of often interlinked political, cultural, economic, institutional, geographical, and demographic factors influence how climate change will or will not impact health, including social exclusion, inequities, and differential access to and control over social, financial, and environmental resources that are required for adaptation and resilience. ${ }^{2}$ Given these multifaceted, widespread, and complex impacts on human health, understanding how climate change impacts human health and the ways to best respond are grand and defining challenges of our time. Indeed, this grand challenge has been identified by two Lancet Commissions, ${ }^{1,3}$ the World Health Organization (WHO), ${ }^{4}$ and the Medical Association of Canada, ${ }^{5}$ the United States, ${ }^{6}$ and Britain. ${ }^{7}$

While the threat of climate change to health is unequivocal and pressing, ${ }^{2,3}$ climate change is increasingly being presented as a public health opportunity. ${ }^{1}$ For instance, the negative health outcomes resulting from climate change could be reduced with enhanced healthcare provision and public health services, improved disaster management, integrated environment and health surveillance and early warning systems, poverty reduction, and mainstreaming cross-sector collaboration. ${ }^{2}$ Furthermore, there are several health co-benefits of climate change mitigation, ranging from improved physical activity resulting from active commuting, to reduced respiratory illnesses from decreased air pollution. ${ }^{2}$ While the health sector is already grappling with climate change impacts on public health and healthcare needs, priorities, use, provision, and costs, health adaptation is generally under-represented in policies, planning, and programming. For instance, all initiatives under the United Nations Framework Convention on Climate Change (UNFCC) affect human health; however, only $15 \%$ of initiatives had an explicit human health component described. ${ }^{8}$

Canada is no exception to this global trend, with the health sector substantially under-represented in adaptation initiatives compared to other sectors. ${ }^{8}$ Of the health sector adaptation actions, many efforts by governments have been groundwork actions, with initiatives focused on building adaptive capacity and preparing conditions to enable adaptation, including increasing awareness about the health impacts of climate change and conducting vulnerability assessments. ${ }^{8-10}$

There have been an increasing number of government adaptation actions which are aimed at reducing vulnerability, including warning and monitoring systems, as well as initiatives aimed at changing practice and behaviour. In Canada, this has included training, information resources, frameworks, general outreach and education, and dissemination of information to decision makers. ${ }^{9}$ Importantly, health adaptation is occurring at the local level, ranging from individual, to household, to community scales.

Considering the research gaps, public health practice challenges and opportunities, as well as the urgency of climate change impacts on human health, the six contributions to this Special Issue, published in conjunction with Earth Day, illustrate the many ways in which climate change is already impacting individual and community health. Through a combination of at-a-glance papers and original research articles, this collection demonstrates a diversity of research on climate change and health in Canada and is a clear call to action for the health sector to support both climate change health adaptation measures, and to champion mitigation strategies that have clear associated health co-benefits.

This Special Issue begins with a synthesis of climate-sensitive health concerns in the literature in rural and remote regions in Canada by Kipp et al. ${ }^{11}$ Utilizing a scoping review search process, this article identifies the key health vulnerabilities and strengths of rural and remote regions, and discusses challenges associated with food and water security, exacerbation of chronic illness, infectious diseases, morbidity and mortality, and mental health.

\section{Author references:}

1. Labrador Institute, Memorial University, Happy Valley-Goose Bay, Labrador, Canada

2. School of Public Health, University of Alberta, Edmonton, Alberta, Canada

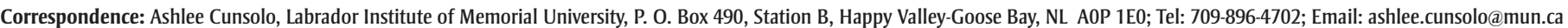
Sherilee L. Harper, School of Public Health, University of Alberta, 1140587 Avenue NW, Edmonton, AB T6G 1C9; Tel: 780-492-7766; Email: sherilee.harper@ualberta.ca 
Indigenous Peoples, including First Nations, Inuit, and Metis communities, are often experiencing disproportionate impacts from climate change on their health and wellbeing. Richards et al. ${ }^{12}$ describe the Climate Change and Health Adaptation Program within the First Nations and Inuit Health Branch of Indigenous Services Canada, which funds community adaptation research with the objective of developing community-based and culturally-sensitive tools and solutions. Drawing from three case studies, the authors identify the diverse research funded through this program and emphasize the importance not only of funding climate change and health research, but of directly supporting Indigenous communities to do their own work, based on their local contexts and cultures.

Underscoring the important focus on cobenefits, Kingsley ${ }^{13}$ examines the ways in which protecting, improving, and increasing green spaces can be not only a climate change mitigation strategy, but also an important health strategy, with positive benefits for chronic diseases and their associated risk factors. Drawing from two examples of multi-sectoral collaborations, including EcoHealth Ontario and Climate Change Parks in Scotland, this contribution puts forward a model that considers green spaces as an important climate change and health intervention.

Demers and Gosselin ${ }^{14}$ examine the increase of pollen allergies and seasonal allergic rhinitis in North America from a changing climate, particularly from ragweed. Through an analysis of a strategy implemented by the Quebec government to decrease ragweed and related allergenic pollens, this paper examines the scientific data underpinning the strategy, and demonstrates initial successes from its implementation.

MacIntyre et al. ${ }^{15}$ examine the ways in which risk communication related to extreme weather events and climate change occurs in the public health domain. Utilizing a scoping review approach, the authors sought to evaluate public health risk communication strategies, and the implications of these findings for the Ontario Public Health Standards 2018. Their findings indicate that risk communication is more effective when linked to short-term extreme weather events. Such findings are important for informing public health communication strategies and for motivating local actions to mitigate the effects of climate change.

Finally, using a narrative methodology approach, Malena-Chan ${ }^{16}$ studies the ways in which young community leaders in Saskatchewan are interpreting and understanding climate change. Findings from this study suggest that narrative dissonance - or the ways in which narratives of climate change cannot be reconciled because of emotional, moral, or conceptual contradictions - can be an explanatory factor in understanding immobilization and inaction, with implications for public health messaging.

In 2015, the Lancet's multidisciplinary Commission on Climate Change and Health made ten recommendations to governments, including urging them to: "invest in climate change and public health research"; "finance climate-resilient health systems"; and "collaborate to implement policies that mitigate climate change and promote public health, and monitor progress over the next 15 years."17 Building on those recommendations and supporting the growing body of scientific literature, this Special Issue exemplifies the diversity of pathways through which climate change is currently impacting the health of Canadians, while underscoring both the grand health challenges and the grand health opportunities from a changing climate.

\section{Conflicts of interest}

The authors have no conflicts of interest to declare.

\section{Authors' contributions and statement}

AC and SLH contributed equally to the conceptual development, writing, and editing of this manuscript.

The content and views expressed in this article are those of the authors and do not necessarily reflect those of the Government of Canada.

\section{References:}

1. Wang H, Horton R. Tackling climate change: the greatest opportunity for global health. Lancet. 2015;386(10006): 7-13.
2. Smith KR, Woodward A, CampbellLendrum D, et al. Human health: impacts, adaptation, and co-benefits. In: Field CB, Barros VR, Dokken DJ, et al., editors. Climate Change 2014: Impacts, Adaptation, and Vulnerability Part A: Global and Sectoral Aspects Contribution of Working Group II to the Fifth Assessment Report of the Intergovernmental Panel on Climate Change. London (UK): Cambridge University Press; 2014. p. 709-54.

3. Costello A, Abbas M, Allen A, et al. Managing the health effects of climate change. Lancet. 2009;373(9676): 1693-733.

4. World Health Organization. COP24 special report: health \& climate change. Geneva (Switzerland): World Health Organization; 2018. 38 p.

5. Canadian Medical Association. Climate change and human health. Canadian Medical Assocation policy statement [Internet]. Ottawa (ON): Canadian Medical Association; 2010. Available from: http://policybase.cma.ca/dbtw -wpd/Policypdf/PD10-07.pdf

6. American Medical Association. Confronting health issues of climate change [Internet]. American Medical News. 2011. Available from: https:// amednews.com/article/20110404 /opinion/304049959/4/\#exli

7. British Medical Association. BMA backs action on health effects of climate change [Internet]. British Medical Association; 2015. Available from: https://www.bma.org.uk/news/2015 /october/bma-backs-action-on-health -effects-of-climate-change

8. Lesnikowski AC, Ford JD, BerrangFord L, Paterson JA, Barrera M, Heymann SJ. Adapting to health impacts of climate change: a study of UNFCCC Annex I parties. Environ Res Lett. 2011;6(4):044009.

9. Austin S, Ford J, Berrang-Ford L, Araos M, Parker S, Fleury M. Public health adaptation to climate change in Canadian jurisdictions. Int J Environ Res Public Health. 2015;12(1):623-51.

10. Panic M, Ford JD. A review of national-level adaptation planning with regards to the risks posed by climate change on infectious diseases in 14 OECD nations. Int $\mathrm{J}$ Environ Res Public Health. 2013;10(12):7083-109. 
11. Kipp A, Cunsolo A, Vodden K, et al. At-a-glance - Climate change impacts on health and wellbeing in rural and remote regions across Canada: a synthesis of the literature. Health Promot Chronic Dis Prev Can. 2019;39(4): 122-6.

12. Richards G, Frehs J, Myers E, Van Bibber M. Commentary - The Climate Change and Health Adaptation Program: Indigenous climate leaders' championing adaptation efforts. Health Promot Chronic Dis Prev Can. 2019;39(4): 127-30.

13. Kingsley M, EcoHealth Ontario. Commentary - Climate change, health and green space co-benefits. Health Promot Chronic Dis Prev Can. 2019;39(4): 131-5.

14. Demers I, Gosselin P. At-a-glance Pollens, climate and allergies: Quebec initiatives. Health Promot Chronic Dis Prev Can. 2019;39(4):136-41.

15. MacIntyre E, Khanna S, Darychuk A, Copes R, Schwartz B. Evidence synthesis - Evaluating risk communication during extreme weather and climate change: a scoping review. Health Promot Chronic Dis Prev Can. 2019;39(4):142-56.

16. Malena-Chan R. A narrative model for exploring climate change engagement among young community leaders. Health Promot Chronic Dis Prev Can. 2019;39(4):157-66.

17. Watts N, Amann M, Ayeb-Karlsson S, et al. The Lancet Countdown on health and climate change: from 25 years of inaction to a global transformation for public health. The Lancet. 2018;391(10120):581-630. 